\title{
Peripheral Trauma Induced Dystonia or Post-Traumatic Syndrome?
}

\author{
Hrishikesh Kumar, Mandar Jog
}

\begin{abstract}
The relationship between peripheral trauma and dystonia has been debated for more than a century but the issue still remains controversial. There are passionate supporters and detractors of the association and both the groups have their own arguments. This review aims to critically evaluate those arguments and presents current understanding of this association. In the process, the relevant case series and scientific papers exploring this subject have been discussed. Upon careful review of available literature coupled with their own experience, the authors believe that peripheral trauma can predispose to abnormal posturing of a body part after variable intervals. To call this posturing a "post-traumatic dystonia" might be premature and the term "post-traumatic syndrome" can be used instead. More work is needed to unravel the pathophysiology of this post-traumatic syndrome.
\end{abstract}

\begin{abstract}
RÉSUMÉ: Dystonie induite par un traumatisme périphérique ou syndrome post-traumatique? La relation entre le traumatisme périphérique et la dystonie est un sujet de controverse depuis plus de cent ans. Il y a des supporteurs et des détracteurs passionnés de cette relation et les deux groupes ont des arguments qui leur sont propres. Le but de cette revue était d'évaluer de façon critique ces arguments et de présenter les connaissances actuelles concernant cette relation. Les séries de cas pertinentes et les articles scientifiques sur ce sujet ont été examinés dans la discussion. Suite à une revue attentive de la littérature et compte tenu de leur propre expérience, les auteurs croient que le traumatisme périphérique peut prédisposer à une gesticulation d'une partie du corps après un intervalle variable. Il pourrait être prématuré de nommer cette dystonie de posture "dystonie post-traumatique" et le terme "syndrome post-traumatique" peut être utilisé à sa place. Il faudra effectuer des travaux supplémentaires pour faire la lumière sur la physiopathologie de ce syndrome post-traumatique.
\end{abstract}

Can. J. Neurol. Sci. 2011; 38: 22-29

Dystonia is defined as abnormal movement characterized by sustained muscle contractions, frequently causing twisting and repetitive movements or abnormal postures. ${ }^{1}$ Multiple movement disorders have been related to trauma but posttraumatic dystonia has aroused maximum interest. ${ }^{2-6}$ It is generally accepted that central trauma can cause dystonia with or without structural changes on neuro-imaging., ${ }^{2,7}$ On the other hand, the concept of peripheral trauma induced dystonia (PTD) remains ambiguous. ${ }^{9-13}$

The existence of idiopathic dystonia as an organic entity was itself historically challenged. ${ }^{14}$ Better understanding of the physiological basis of dystonia may have contributed to its acceptance as a true neurological entity. The basal gangliathalamo-cortical circuit has been implicated in the pathogenesis of dystonia. ${ }^{15}$ Recent literature indicates a wider, network level dysfunction in the nervous system. ${ }^{16-18}$ Dystonia is now considered a manifestation of aberrant neuronal networks that are involved in sensori-motor processing required for the control and execution of voluntary movement. ${ }^{18-20}$ It is possible that the association between peripheral trauma and dystonia could also follow a similar course and PTD could be either proven or disproven as a true organic entity. However, the understanding of the pathophysiology of PTD is less clear. This paper will present arguments and counter-arguments for PTD as they are currently available in the literature (Table 1). Since the association between abnormal posturing and trauma has been termed "posttraumatic dystonia" in available literature, we will use this term throughout the paper until the conclusion where the nomenclature of this condition will be discussed. The following discussion about PTD includes two patient subgroups- those developing dystonia soon after trauma as well as those developing dystonia much later after trauma.

From the Movement Disorders Program, London Health Sciences Centre, University of Western Ontario, London, Ontario, Canada.

Received April 5, 2010. Final Revisions Submitted June 29, 2010.

Correspondence to: Hrishikesh Kumar, Movement Disorders Program, London Health Sciences Centre, 339 Windermere Road, London, Ontario, N6A 5A5, Canada. 


\section{I: ABUNDANCE OF CASE REPORTS OF PTD}

\section{Arguments in support of association between peripheral trauma and dystonia}

In 1888 Gower discussed a case of a naval officer who presented with writer's cramp after wrist sprain..$^{21}$ The case was probably the earliest report of peripheral trauma related to dystonia. In the context of etiology of occupational cramps, Wilson in 1955 had written, "injury, too such as sprain, has been known to bring on the trouble". ${ }^{22}$ Since these early observations, multiple cases and a few case control studies have been reported and diagnostic criteria for PTD have been proposed. Cervical dystonia is the most commonly reported PTD; peripheral trauma has been implicated in 5-21\% of cases of cervical dystonia in different series. ${ }^{23-29}$ Sheehy and Marsden observed that $9 \%$ of patients with spasmodic torticollis had a preceding history of peripheral trauma. ${ }^{23}$ Samii and colleagues found history of head and neck trauma in 14 out of 114 consecutive patients with cervical dystonia within one year preceding the onset of dystonia. ${ }^{27}$ O'Riordan and Hutchinson reported history of local trauma in 16 out of 95 patients of cervical dystonia. ${ }^{28}$ The latter two studies also compared the clinical characteristics of the PTD patients with the patients of cervical dystonia having no history of preceding trauma. An Italian movement disorder study group, in a large multi-centric case control study, studied various possible risk factors for primary generalized dystonia. ${ }^{30}$ The study found a significant positive association between local body injury and dystonia of same body part. Schott (1985) reported four patients with either axial or arm dystonia after local trauma. ${ }^{24}$ Later in 1986 , the author published a series of ten patients in whom dystonia was possibly induced by peripheral trauma. ${ }^{31}$ In that case series the time-interval between trauma and appearance of dystonia was 48 hours to three years. Sankhla, Lai and Jankovic reported 27 patients of oromandibular dystonia where the onset was preceded by oromandibulo-facial trauma including dental procedures. ${ }^{32}$ They included only those cases who had onset of dystonia within one year of trauma. Schrag and colleagues reported eight cases of mandibular dystonia developing hours to months following various dental procedures. ${ }^{33}$ Tarsy found history of preceding local trauma in $9 \%$ cases of cervical dystonia. The author also explored the clinical difference between acute onset PTD and delayed onset PTD. ${ }^{34}$ Truong and colleagues reported six cases of cervical dystonia developing within four days of local trauma. ${ }^{35}$

These are only a few examples among the vast number of cases available in the literature. The range of trauma-severity and the time-line of appearance of dystonia after the trauma were varied in these cases. The majority of the patients had significant local pain after trauma and dystonia was limited to the body part affected by the trauma. The number of reported cases itself is an argument to support a causative role of peripheral trauma in the induction of dystonia.

\section{Counter arguments}

1. Denominator-problem is the major criticism of the above argument. ${ }^{11}$ Peripheral trauma is extremely common and it is almost impossible to determine a denominator. Post-traumatic dystonia is very rare in comparison. It might be possible that the association is only a chance co-occurrence.
2. The severity of trauma was extremely variable in the reported cases (tonsillectomy, tooth extraction, ill-fitting denture, mild bruises after slipping on ice, bumping the head into car door, whip-lash etc). Reported duration between trauma and appearance of dystonia varied from immediate up to many years. Upon examining such wide variations in intensity and latency of onset, one might suspect that many of these cases probably had idiopathic dystonia and the association with trauma was spurious. Moreover, a history of mild trauma is always suspect and suggestible in cases having dystonia-onset long after the trauma.

3. Criticism of the result of case-control study performed by the Italian movement disorders group ${ }^{30}$ : One of the members of the group later commented that the study was an exploratory one, it assessed large number of variables, and was more liable to false positive results than an ad-hoc hypothesis testing study. ${ }^{36}$ Later, an ad-hoc multicentric case-control study did not find differences in the frequency of vault or maxilla-facial trauma between cranial dystonia patients and a suitable control population. ${ }^{37}$ In another case-control study, no significant association was found between writer's cramp and upper limb trauma. ${ }^{38}$

\section{Presence of psychiatric or legal factors in many CASES IMPLIES NON-ORGANIC OR FALSE ASSOCIATION}

\section{Argument supporting pseudo-association between trauma and dystonia}

Malingering, psychogenic factors and presence of known psychiatric conditions can result in false association between peripheral trauma and dystonia. Many of the reported cases of PTD had legal issues pending and a malingering or psychogenic component was suspected. ${ }^{13,39,40}$ Kurlan, Brin and Fahn reported a patient who developed reflex sympathetic dystrophy followed by multiple abnormal movements (including dystonia) after minor left hand trauma. ${ }^{39}$ Two movement disorder specialists examined that patient separately and both of them testified that the abnormal movements could be the result of trauma. On the recommendation of the attorney, video surveillance was done and the patient turned out to be a malingerer. Verdugo and Ochoa examined 58 patients with complex regional pain syndrome (CRPS) with abnormal movements and they found that all of their patients displayed nonorganic pseudo-neurological manifestations. ${ }^{40}$ Malingering was documented by secret video surveillance in four of their patients. Sa and colleague studied 16 patients of post-traumatic cervical dystonia and found that litigation or compensation was involved in all of them. ${ }^{13}$ The authors found that psychological conflict, stress, or both were being expressed via somatic channels in 11 of the 12 tested patients. These cases create doubt about the true nature of PTD and dystonia related to CRPS.

Depression and other psychiatric features were also frequently reported in cases of PTD. In a series of torticollis presented by O'Riordan and Hutchinson, depression was found in 14 out of 16 patients in the post-traumatic group whereas only 28 out of 52 cases had depression in the non-traumatic group. ${ }^{28}$ However, proportions of patients requiring drug treatment for depression in these two groups were the same. Schrag and colleagues meticulously examined 103 patients of fixed 
Table 1: Arguments for and against the association between peripheral and dystonia (summarized, with corresponding references)

\begin{tabular}{|c|c|c|c|c|}
\hline Argument & $\begin{array}{l}\text { Evidence in } \\
\text { favour of } \\
\text { PTD }\end{array}$ & Reference & $\begin{array}{l}\text { Evidence } \\
\text { against PTD }\end{array}$ & Reference \\
\hline $\begin{array}{l}\text { Case reports } \\
\text { of post- } \\
\text { traumatic } \\
\text { dystonia }\end{array}$ & $\begin{array}{l}\text { Abundance of } \\
\text { reported cases } \\
\text { itself an } \\
\text { argument in } \\
\text { favour of } \\
\text { existence }\end{array}$ & $21-35$ & $\begin{array}{l}\text { Association is } \\
\text { not real. } \\
\text { Peripheral } \\
\text { trauma is } \\
\text { extremely } \\
\text { common and } \\
\text { it is difficult } \\
\text { to know the } \\
\text { denominator. }\end{array}$ & $11,36,37,38$ \\
\hline $\begin{array}{l}\text { Malingering/ } \\
\text { secondary } \\
\text { gain/ } \\
\text { psychogenic/ } \\
\text { psychiatric } \\
\text { features } \\
\text { reported in } \\
\text { PTD patients }\end{array}$ & $\begin{array}{l}\text { Many } \\
\text { reported } \\
\text { patients did } \\
\text { not have any } \\
\text { of these } \\
\text { features. } \\
\text { Associated } \\
\text { psychiatric } \\
\text { disorder does } \\
\text { not rule out } \\
\text { organicity. }\end{array}$ & $32,34,38$ & $\begin{array}{l}\text { Presence of } \\
\text { these features } \\
\text { indicates that } \\
\text { association } \\
\text { between } \\
\text { trauma and } \\
\text { dystonia can } \\
\text { be spurious. }\end{array}$ & $13,32,34,41$ \\
\hline $\begin{array}{l}\text { PTD is } \\
\text { clinically } \\
\text { different } \\
\text { from } \\
\text { dystonia- is } \\
\text { it a non } \\
\text { dystonic } \\
\text { entity? }\end{array}$ & $\begin{array}{l}\text { Some case } \\
\text { reports did } \\
\text { not find any } \\
\text { clinical } \\
\text { difference } \\
\text { between PTD } \\
\text { and non- } \\
\text { trauma related } \\
\text { dystonia. } \\
\text { Despite being } \\
\text { different } \\
\text { clinically in } \\
\text { other reported } \\
\text { cases, they } \\
\text { conform to } \\
\text { the definition } \\
\text { of dystonia. }\end{array}$ & 27,32 & $\begin{array}{l}\text { Abnormal } \\
\text { posturing } \\
\text { occurring } \\
\text { after trauma } \\
\text { differs } \\
\text { clinically } \\
\text { from dystonia } \\
\text { (table 2). } \\
\text { Post- } \\
\text { traumatic } \\
\text { abnormal } \\
\text { posturing may } \\
\text { be non- } \\
\text { dystonic. }\end{array}$ & $28,33,34,35$ \\
\hline $\begin{array}{l}\text { Experimental } \\
\text { evidence } \\
\text { suggesting } \\
\text { cortical re- } \\
\text { organization } \\
\text { and resultant } \\
\text { dystonia in } \\
\text { response to } \\
\text { abnormal } \\
\text { peripheral } \\
\text { input }\end{array}$ & $\begin{array}{l}\text { Animal and } \\
\text { imaging study } \\
\text { suggest } \\
\text { cortical re- } \\
\text { organization } \\
\text { on repeated } \\
\text { peripheral } \\
\text { stimuli } \\
\text { (including } \\
\text { pain). Cortical } \\
\text { re- } \\
\text { organization } \\
\text { might be } \\
\text { underlying } \\
\text { mechanism } \\
\text { for dystonia. }\end{array}$ & $85-89$ & $\begin{array}{l}\text { Evidence for } \\
\text { cortical re- } \\
\text { organization } \\
\text { itself not } \\
\text { convincing. } \\
\text { Link between } \\
\text { cortical re- } \\
\text { organization } \\
\text { and } \\
\text { occurrence of } \\
\text { dystonia } \\
\text { missing. }\end{array}$ & 11,36 \\
\hline
\end{tabular}

dystonia- DSM IV criteria for somatization disorder and Fahn \& Williams classification criteria for psychogenic dystonia were used by them. ${ }^{41,42}$ Thirty-seven percent of patients fulfilled the classification criteria for documented or clinically established psychogenic dystonia and 29\% of patients fulfilled the DSM IV criteria for somatization. A peripheral injury preceded dystonia in $63 \%$ of patients and $20 \%$ of patients fulfilled the criteria of complex regional pain syndrome. ${ }^{41}$

\section{Counter-argument}

1. Malingering can be expressed as any movement disorder (including tremor, parkinsonism and dystonia) but that does not rule out the existence of the condition as an organic entity in the rest of the cases. None of the patients reported by Sankhla and colleagues $^{32}$ had psychiatric problems, pending litigation or secondary gain. Among the 103 patients of fixed dystonia reported by Schrag and colleagues, there was a subgroup of patients who had a history of preceding trauma but did not have any psychogenic issues. ${ }^{41}$

2. It is well known that many of the accepted movement disorders have psychiatric components. The presence of major depression and obsessive compulsive behavior among other psychiatric symptoms is well documented in genetically proven cases of dystonia (e.g. DYT 1 and DYT 11) ${ }^{43,44}$ Obviously the existence of psychopathology does not always imply a nonorganic etiology to dystonia.

\section{DIAGNOSTIC CRITERIA}

The following criteria were proposed by Cardoso and Jankovic for the diagnosis of peripheral trauma induced movement disorders. ${ }^{45}$ The criteria were followed by subsequent studies to diagnose PTD. ${ }^{28,32}$

1. Trauma is severe enough to cause local symptoms for at least two weeks or requires medical evaluation within two weeks after trauma.

2. Initial manifestation of the movement disorder is anatomically related to the site of injury.

3. Onset of movement disorder is within days or months (up to one year) after the injury.

\section{Diagnostic criteria for post-traumatic dystonia- are they helpful ?}

In the absence of a gold standard, any criteria for PTD would be arbitrary and cannot be validated. Following diagnostic criteria for such a poorly understood condition may result in the inclusion of only those patients that meet the criteria, thereby losing any flexibility to modify and improve our understanding of the condition. It is important to note that the above criteria do not mention the clinical features of PTD, implicitly accepting that PTD and idiopathic dystonia might not be clinically different. We review the individual points of above-mentioned criteria in the following sections.

\section{Severity of trauma}

The perception of what constitutes significant trauma is a personal determination. Seeking medical advice may depend upon such perceptions. Also, since post-traumatic symptoms can improve fairly quickly, patients may experience the most severe symptoms only for a few days and while the condition may not have completely improved, severity falls below the threshold for seeking medical advice. This makes the two weeks rule arbitrary. Access to medical advice within two weeks may also depend on availability of the facility, geographical, cultural, educational and economic factors. 


\section{Anatomical site of dystonia}

A vast majority of reported cases of PTD had dystonia-onset in the anatomical site affected by trauma. That is understandable as one of the popular underlying mechanisms is neural reorganization of the corresponding sensory-motor area. ${ }^{46}$ However, in a connected neural system, reorganization resulting in one area can be expected to spread to another, which might apply in cases of PTD.

\section{Duration criteria}

The time of dystonia-onset after trauma was variable in different case series. Some of the reported cases had onset of dystonia a few years after the trauma. ${ }^{31,47}$ Thus proposing any arbitrary time-line between peripheral trauma and onset of dystonia will be unsatisfactory. Lessons can also be learnt from the examples of dystonia resulting from well documented central trauma. The reported time-line between the central trauma and appearance of dystonia was 0 to 14 years in various case series. ${ }^{48-50}$ Many of those patients developed dystonia much later than one year after head-injury. There is no reason to accept that the onset of dystonia should only occur within one year of trauma in cases of PTD.

\section{IV: Is PTD A NON-DYSTONIC ENTITY?}

\section{Argument supporting PTD as a non-dystonic entity}

Truong and colleagues reported six cases of post-traumatic torticollis and all of them developed dystonia within four days of trauma. ${ }^{35}$ They all had marked limitation of range of movement, lack of improvement during sleep, absence of sensory tricks and spasm of para-spinal muscles. Anticholinergics were ineffective in these cases and botulinum toxin injection resulted in "some" benefit. O'Riordan and Hutchinson reported 16 cases of posttraumatic cervical dystonia and compared this group with nontraumatic cervical dystonia. ${ }^{28}$ All their PTD cases had onset of dystonia within two weeks of trauma. The authors found that the trauma group had a significantly increased frequency of lateralcollis, had more pain and displayed higher frequency of depression. Non-significant trends were noticed for less responsiveness to botulinum toxin injection and less use of sensory tricks. The authors suggested that early onset PTD can be a distinct entity. Tarsy found two clinical patterns in the cases of post-traumatic cervical dystonia. ${ }^{34}$ Late onset cases (those developing dystonia after 12 weeks of trauma) were clinically similar to idiopathic dystonia. But dystonia in early onset cases (those developing dystonia within four weeks of trauma) was characterized by acute onset, rapid evolution of pain and cervical spasm, reduced cervical mobility in all directions, prominent shoulder elevation, trapezius hypertrophy, absence of spasmodic involuntary movements of the head and neck, lack of response to sensory tricks or activation maneuvers, and poor response to botulinum toxin injection. ${ }^{34}$ Schrag and colleagues studied 103 cases of fixed dystonia and concluded that they usually but not always occurred after peripheral injury and overlapped with complex regional pain syndrome. ${ }^{41}$

All these papers used the word "dystonia" in describing the clinical features of their patients with post traumatic posturing of neck or other body parts. However, most of the above patients (except late onset cases of Tarsy) ${ }^{34}$ had clinical features distinct from idiopathic dystonia (Table 2). This departure in clinical features of PTD from idiopathic dystonia is used as an argument to consider PTD as a "non-dystonic" entity. Sa and colleagues proposed the term "post-traumatic painful torticollis" for such patients with post traumatic cervical dystonia. ${ }^{13}$ Tarsy suggested that his acute onset post-traumatic dystonia patients might have had a "non-dystonic muscle spasm" instead of true dystonia. ${ }^{34}$

\section{Counter-arguments}

Some case series could not find any clinical difference between PTD and idiopathic dystonia, irrespective of time of onset after peripheral trauma. Sankhla and colleagues compared 27 patients with post-traumatic oro-mandibular dystonia to 21 patients with idiopathic oro-mandibular dystonia. ${ }^{32}$ They found no difference in clinical presentation, no difference in action or resting component of dystonia, no difference in response to sensory tricks, and no difference in response to botulinum toxin injection. Samii et al compared trauma related cervical dystonia with idiopathic cervical dystonia and found no clinically significant difference in clinical features, response to sensory tricks and responsiveness to botulinum toxin. ${ }^{27}$

Arguments to refute PTD on the basis of atypical clinical features are also weakened by the intrinsic differences in the clinical presentation of dystonia itself. Patients with well known genetic dystonia are not uniform in their presentation and have variable response to botulinum toxin.

\section{Proposed mechanisms of PTD}

The mechanism of generation of PTD can be summarized from the literature as being an input induced, aberrant or maladaptive reorganization within the nervous system. This reorganization could occur from peripheral input resulting from noxious, task-induced and non-noxious (tactile or vibration) sensory stimulation. The mal-adaptation could then occur at any level of the neuraxis. The following paragraphs will review the hypotheses and available evidence. We will discuss three specific situations that highlight abnormal input conditions noxious stimuli, repetitive tasks and non-noxious stimuli. Using these as models of abnormal input, we will then review the maladaptations occuring at the various levels of the neuraxis.

\section{V.1. SPECIFIC SITUATIONS THAT HIGHLIGHT ABNORMAL INPUT}

\section{A) Noxious sensory input (Example: Complex regional pain syndrome, CRPS)}

Complex regional pain syndrome is a post-traumatic condition frequently associated with later onset of musclespasm, abnormal posturing, or dystonia in the affected body part. As in other cases of PTD, CRPS also corresponds to abnormal noxious sensory input resulting in dystonia. Thus, CRPS related dystonia can serve as a model for study of PTD.

- Definition of CRPS: The International Association for Study of Pain (IASP) defines CRPS as a post-injury condition that is characterized by spontaneous pain disproportionate to the inciting event and not limited to the territory of a single peripheral nerve. ${ }^{51}$ Patients also have edema, skin blood flow abnormality, or abnormal sweating in the region of the pain. Type I CRPS (formerly named Reflex Sympathetic Dystrophy or Sudeck's Atrophy) develops following an initiating noxious 
Table 2: Difference between clinical presentation of post-traumatic dystonia and non-trauma related dystonia (based on reference $\mathrm{e}^{2,28,33,34}$ ).

\begin{tabular}{l|l|l}
\hline & Post traumatic dystonia & Non trauma related dystonia \\
\hline $\begin{array}{l}\text { Onset and progression } \\
\text { part }\end{array}$ & Acute to sub-acute onset, rapid progression & Insidious onset, slow progression \\
\hline Presence of pain & $\begin{array}{l}\text { Marked limitation in range of movement } \\
\text { (more fixed component) }\end{array}$ & $\begin{array}{l}\text { Relative preservation of range of movement } \\
\text { (more mobile) }\end{array}$ \\
\hline Improvement during sleep & Painful spasms & Painless \\
\hline Use of sensory trick & Less common & Improves during sleep \\
\hline Posture in cervical dystonia & Lateral-collis more common & More common \\
\hline Response to botulinum toxin & Less responsive to toxin & Better response to toxin \\
\hline
\end{tabular}

event not related to nerve injury, while type II CRPS (formerly named Causalgia) develops after a nerve injury. Presence of movement disorders was included in the research criteria for CRPS proposed by Bruehl and colleagues. ${ }^{52}$

- Association between CRPS and dystonia: Marsden and colleagues described muscle spasm in a case of Sudeck's atrophy in $1984 .{ }^{53}$ In the case series reported by Jankovic and Van der Linden, nine patients had focal dystonia associated with posttraumatic reflex sympathetic dystrophy. ${ }^{25}$ Bhatia, Bhatt and Marsden also elaborated upon the association and named the condition causalgia-dystonia syndrome..$^{54}$

Reports of development of dystonia in a large number of patients of CRPS further supported the association. ${ }^{55-60}$ Reported prevalence of dystonia in CRPS has varied between $5 \%$ to up to $60 \%$ in these series. Interval between non-motor features of CRPS and onset of dystonia varied from days to a few years. ${ }^{54-56}$ The onset of dystonia could be acute or insidious, and the posturing may be mobile or fixed. ${ }^{55}$ Dystonia may progress long after CRPS has subsided. ${ }^{54}$ Patients with post-traumatic CRPS and dystonia were found to be younger than those without dystonia. ${ }^{55}$ Immobilization of the limb was found to be a risk factor for developing dystonia in some patients. ${ }^{55,56}$ There is no consensus whether patients with CRPS-dystonia exhibit a distinct psychological profile..$^{61,62}$

- Features of CRPS related dystonia: Complex regional pain syndrome related to dystonia typically produces flexion of the fingers and wrist in the upper limb with relative sparing of thumb and index finger, and inversion with plantar flexion of the foot with clawing of the toes in the lower limbs. ${ }^{58}$ Complex regional pain syndrome and dystonia initially develop in the same body part which was affected by peripheral trauma. Proximal spread of dystonia was reported in some of the patients. ${ }^{54,56,58}$ The areas affected by dystonia and CRPS may then no longer overlap. Dystonic involvement of other areas can be related to a new injury or can be spontaneous. ${ }^{54,56}$ Even multifocal and generalized spread has been reported. ${ }^{60}$ The spread and progression after disappearance of symptoms of CRPS might be related to central factors. ${ }^{54,58}$ The mechanisms of development of dystonia in CRPS are thought to overlap with the mechanisms in cases of PTD without CRPS - Spinal and cortical disinhibition documented in CRPS with or without dystonia is quite similar to the current network concept of dystonia pathogenesis. . $^{9} 16,63,64$

\section{B) Repetitive tasks}

It can be argued that task specific dystonia is also a peripherally generated condition. While movements can act as peripheral sensory input leading to cortical re-organization, can these repeated tasks be viewed as trauma? Topp and Byl demonstrated re-organization of hand representation in the contralateral somatosensory areas of two owl monkeys who developed task specific movement dysfunction. ${ }^{65}$ They concluded that repetitive, stereotypical motor behaviors can lead to motor control problems without local signs of tendon or nerve inflammation. In contrast, $\mathrm{Coq}$ and colleagues found dramatic re-organization of fore-paw area in sensory cortex on repetitive movements in a rat model but they found signs of local peripheral inflammation (elevated Interleukin 1 beta and Tumor Necrosis Factor alpha). ${ }^{66}$ The authors concluded that both peripheral inflammation and cortical neuroplasticity jointly contribute to the development of chronic repetitive motion disorders. Elliott and colleagues found increased spinal cord pronociceptive neurochemicals on highly repetitive tasks. They thought this to be directed by forelimb muscle inflammation and pain. ${ }^{67}$

\section{C) Non-noxious sensory input}

Response to sensory tricks and association of dystonia with CRPS underscores the sensory aspect of dystonia. Using clinical observations and experimental evidence available until 1995, Hallet proposed that dystonia could be primarily a sensory disorder. ${ }^{20}$ An observation by Merzenich and colleagues was mentioned in that paper, where frequent simultaneous sensory stimulation of a primate hand resulted in distortion of sensory 
receptive fields in the sensory cortex. Those animals developed a motor coordination disorder with posturing similar to dystonia. Reilly and colleagues reported altered N30 components of median nerve Somato-sensory Evoked Potential in cases of dystonia. ${ }^{68}$ Tempel and Perlmutter demonstrated a vibration induced decrease in regional cerebral blood flow in primary sensory cortex and supplementary motor area in the patients with dystonia. ${ }^{69}$ Later, Kaji and colleagues compared the effect of vibration in patients with writer's cramp with control group. ${ }^{70}$ They concluded that the muscles involved in dystonic movements have abnormal sensitivities to vibration at rest and muscle afferents may play a pivotal role in producing dystonic movements. The authors further suggested a possible role of spindle blockade in the treatment of dystonia. Afferent spindle blockade can partially explain the effect of botulinum toxin in writer's cramp as the improvement is more dramatic than the weakness it causes. ${ }^{71}$

The above arguments and evidence support the notion that sensory processing in dystonia may be impaired and repeated sensory input may cause re-organization and maladaptation in the neuraxis.

\section{V.2. MALADAPTATIONS AT VARIOUS LEVELS IN THE NEURAXIS}

\section{A) Changes at the peripheral level (neurogenic inflammation)}

There is ample evidence that peripheral trauma results in neurogenic inflammation of affected body parts..$^{72,73}$ The reason for altered inflammatory response is not known, but cutaneous immune cells along with $\mathrm{C}$ and A delta sensory nerve fibers may play an important role. ${ }^{72}$ It is worth noting that $\mathrm{C}$ and $\mathrm{A}$ delta fibers are also important in the nociceptive withdrawal reflex (NWR). ${ }^{74,75}$

\section{B) Changes at spinal level}

Through retrograde transport, peptides including substance-P reach lamina I of the dorsal horn of spinal cord and may cause long term potentiation, thus enhancing synaptic transmission..$^{9,76}$ It is possible that enhanced synaptic transmission at the dorsal horn level leads to exaggerated NWR. Animal models of neurogenic inflammation have also shown exaggerated NWR. ${ }^{77}$ Nociceptive withdrawal reflex itself is manifested by flexion response in upper limbs and plantar-flexion in lower limbs. This is the pattern seen in majority of patients with PTD and this further strengthens the notion that exaggerated NWR has a central role in PTD. Decreased presynaptic Gamma Aminobutyric acid inhibition was also suggested in CRPS patients with dystonia. ${ }^{78,79}$ Gamma Aminobutyric acid is an inhibitory peptide and its reduction leads to central disinhibition which may result in pain, allodynia and hyperalgesia (through pain fiber disinhibition) and dystonia (through NWR disinhibition).

\section{C) Changes at the supraspinal level}

The thalami, the basal ganglia and even cerebellum are thought to be involved in pain perception. ${ }^{80-82}$ It has been postulated that the basal ganglia undergo plastic changes in response to peripheral sensory input, possibly resulting in dystonia. ${ }^{83}$ In 2005, Braz and colleagues identified small diameter, IB4-positive neurons in the dorsal root ganglia of mice. ${ }^{84}$ In contrast to the classical spinothalamic pathway, these neurons bypass the thalamus and project to various limbic structures and globus pallidus. If present in man, this pathway can provide an anatomical link between the peripheral pain and central somato-sensory structures, the limbic system, and the basal ganglia.

\section{D) Changes at the cortical level}

Reorganization of the somato-sensory area and supplementary motor area on repeated sensory stimulation was shown by Byl, Merzenich and colleagues. ${ }^{85}$ Altered cerebral activation pattern on fMRI was also demonstrated in patients with CRPS-1 linked dystonia upon imaginary movement of affected hand. ${ }^{86}$ The authors speculated that the altered activation pattern reflects an interface between pain-associated circuitry and higher order motor control. Trans-cranial magnetic stimulation and magnetoencephalographic studies suggest motor cortex disinhibition in patients of CRPS ${ }^{87,88}$ Reduced GABAergic inhibition might be central to this cortical disinhibition. ${ }^{58}$ The cortical spread of this abnormal plasticity can explain spread of dystonia to other body parts, as reported in some patients. The cortical spread may also cause changes akin to phenomenon of "kindling," where threshold to produce dystonia in the cortical area representing other body parts is reduced. ${ }^{9,89}$ This might explains the finding of rapid evolution of dystonia in a new limb, even on mild subsequent trauma of that limb, in already known cases of PTD.

\section{CONCLUSION UPON EXAMINING ARGUMENTS AND COUNTER- ARGUMENTS}

Is peripheral trauma associated with subsequent appearance of abnormal posturing (dystonic or non-dystonic) of the corresponding body part?

The issue of denominator problem and presence of secondary gain in many reported cases may make this association appear weak. But the abundance of case reports and a few controlled studies indicate that some relationship exists between the two, which is hard not to acknowledge.

Is post-traumatic abnormal posturing only a peripheral phenomenon or does it have any central component?

Peripheral components, including fixed posturing and local pain are obvious but animal studies and some imaging studies have shown central re-organization on repeated peripheral sensory stimulation. On the basis of these findings, one can speculate that peripheral trauma related abnormal posturing of a body-part is the result of both peripheral and central mechanisms.

Organic or Non-organic/ Dystonic or Non-dystonic?

Although in many patients the condition may have nonorganic origins, it is clear that a state of post-traumatic posturing does exist in a number of patients. Calling this post-traumatic abnormal posturing "dystonic" or "non-dystonic" is a matter of semantics. Abnormal posturing in "PTD" has a more "fixed and painful" component and it differs from classical dystonia in many ways (Table 2). In the absence of a standard diagnostic tool and variations in the presentation of true dystonia itself, post-traumatic posturing is bound to be interpreted differently. Some may call it "dystonia" and others may call it simply abnormal posturing or "post-traumatic syndrome" or "nondystonia torticollis (when it involves the neck)". It is important 
to explore the pathogenesis of the condition and to determine how it is similar to, or distinct from typical dystonia.

\section{Disclosures}

Mandar Jog discloses the following:

- Served on scientific advisory boards for: Allergan (Chair 2008, 2009); Novartis (participant 2008, 2009); Biovail (participant 2009); Teva (Chair/participant 2008, 2009).

- Travel grants for conference proceedings: Teva 2008; 2009; Novartis 2009.

- Served as the Associate Editor for the Canadian Journal of Neurological Sciences 2008, 2009.

- Received honoraria from Novartis, Allergan, Biovail Pharma, and Teva Neuroscience, Merz pharmaceutical, Boehringer Ingelheim, Prestwick pharmaceuticals, GlaxoSmithKline.

- Co-investigator of two pilot study grants received from Parkinson's Society Canada. Recipient of previous and current grants from the Canadian Institutes of Health Research in the role of Primary Investigator.

- Member of board for Parkinson's Society Canada.

\section{REFERENCES}

1. Ad Hoc Committee (1984): Ad Hoc committee of the Dystonia Medical research foundation meeting in February 1984

2. Jankovic J. Post-traumatic movement disorders: central and peripheral mechanisms. Neurology. 1994;44(11):2006-14.

3. Factor SA, Sanchez-Ramos J, Weiner WJ. Trauma as an etiology of parkinsonism: a historical review of the concept. Mov Disord. 1988;3(1):30-6.

4. Hallett M, Chadwick D, Marsden CD. Cortical reflex myoclonus. Neurology. 1979;29(8):1107-25.

5. Drake ME Jr, Jackson RD, Miller CA. Paroxysmal choreoathetosis after head injury. J Neurol Neurosurg Psychiatry. 1986;49(7): 837-8.

6. Jankovic J, Van der Linden C. Dystonia and tremor induced by peripheral trauma: predisposing factors. J Neurol Neurosurg Psychiatry. 1988;51(12):1512-9.

7. Krauss JK, Mohadjer M, Braus DF, Wakhloo AK, Nobbe F, Mundinger F. Dystonia following head trauma: a report of nine patients and review of the literature. Mov Disord. 1992;7(3): 263-72.

8. Lees MS, Rinne JO, Ceballos-Baumann A, Thompson PD, Marsden CD. Dystonia after head trauma. Neurology. 1994;44(8):1374-8.

9. Van Hilten JJ, Geraedts EJ, Marinus J. Peripheral trauma and movement disorders. Parkinsonism Relat Disord. 2007;13 Suppl 3:S395-9.

10. Jankovic J. Can peripheral trauma induce dystonia and other movement disorders? Yes! Mov Disord. 2001;16 (1):7-12.

11. Weiner WJ. Can peripheral trauma induce dystonia? No! Mov Disord. 2001;16 (1):13-22.

12. Thyagarajan D, Kompoliti K, Ford B. Post-traumatic shoulder 'dystonia': persistent abnormal postures of the shoulder after minor trauma. Neurology. 1998;51(4):1205-7.

13. Sa DS, Mailis-Gagnon A, Nicholson K, Lang AE. Posttraumatic painful torticollis. Mov Disord. 2003;18(12):1482-91.

14. Goetz CG, Chmura TA, Lanska DJ. History of dystonia: part 4 of the MDS sponsored history of movement disorders exhibit, Barcelona, June, 2000. Mov Disord. 2001;16(2):339-45.

15. Marsden CD, Obeso JA, Zarranj JJ, Lang AE. The anatomical basis of symptomatic hemidystonia. Brain. 1985;108 (Pt 2):463-83.

16. Mink JW. Abnormal circuit function in dystonia. Neurology. 2006; 66(7):959.

17. Jinna HA, Hess EJ. A new twist to the anatomy of dystonia: the basal ganglia and the cerebellum? Neurology. 2006;67(10): 1769-73.

18. Abbruzzese G, Berardelli A. Sensorimotor integration in movement disorders. Mov Disord. 2003;18(3):231-40.
19. Hallett M. Pathophysiology of dystonia. J Neural Transm Suppl. 2006;(70):485-8.

20. Hallet M. Is dystonia a sensory disorder? Ann Neurol. 1995;38(2): $139-40$.

21. Gowers WR. A manual of disease for nervous system, vol 2. London: Churchill; 1888. p. 659.

22. Wilson SAK. Neurology, vol 3, 2nd ed. London: Butterworth; 1955. p. 1966.

23. Sheehy MP, Marsden CD. Trauma and pain in spasmodic torticollis. Lancet. 1980;1(8171):777-8.

24. Schott GD. The relationship of peripheral trauma and pain to dystonia. J Neurol Neurosurg Psychiatry. 1985;48(7):698-701.

25. Jankovic J, Van der Linden C. Dystonia and tremor induced by peripheral trauma: predisposing factors. J Neurol Neurosurg Psychiatry. 1988;51(12):1512-9.

26. Fletcher NA, Harding AE, Marsden CD. The relationship between trauma and idiopathic torsion dystonia. J Neurol Neurosurg Psychiatry. 1991;54(8):713-7.

27. Samii A, Pal PK, Schulzer M, Mak E, Tsui JK. Post-traumatic cervical dystonia: a distinct entity? Can J Neurol Sci. 2000;27 (1):55-9.

28. O'Riordan S, Hutchinson M. Cervical dystonia following peripheral trauma - a case-control study. J Neurol. 2004;251(2):150-5.

29. Goldman S, Ahlskog EJ. Posttraumatic cervical dystonia. Mayo Clin Proc. 1993;68:443-8.

30. Defazio G, Berardelli A, Abbruzzese G, et al. Possible risk factors for primary adult onset dystonia: a case-control investigation by the Italian Movement Disorders Study Group. J Neurol Neurosurg Psychiatry. 1998;64(1):25-32.

31. Schott GD. Induction of involuntary movements by peripheral trauma. An analogy with causalgia. Lancet. 1986;2:712-15.

32. Sankhla C, Lai EC, Jankovic J. Peripherally induced oromandibular dystonia. J Neurol Neurosurg Psychiatry. 1998;65(5):722-8

33. Schrag A, Bhatia KP, Quinn NP, Marsden CD. Atypical and typical cranial dystonia following dental procedures. Mov Disord. 1999; 14(3):492-6.

34. Tarsy D. Comparison of acute- and delayed-onset posttraumatic cervical dystonia. Mov Disord. 1998;13(3):481-5.

35. Truong DD, Dubinsky R, Hermanowicz N, Olson WL, Silverman B, Koller WC. Posttraumatic torticollis. Arch Neurol. 1991;48 (2):221-3.

36. Defazio G. Does peripheral nerve injury induce dystonia? (No). Moving along. 2010;14(2):1, 9 .

37. Martino D, Defazio G, Abbruzzese G, et al. Head trauma in peripheral cranial dystonia: a multicentric case control study. J Neurol Neurosurg Psychiatry. 2007;78:260-3.

38. Roze E, Soumare A, Pironneau I, et al. Case control study of writer's cramp. Brain. 2009;132:756-64.

39. Kurlan R, Brin MF, Fahn S. Movement disorder in reflex sympathetic dystrophy: a case proven to be psychogenic by surveillance video monitoring. Mov Disord. 1997;12(2):243-5.

40. Verdugo RJ, Ochoa JL. Abnormal movements in complex regional pain syndrome: assessment of their nature. Muscle Nerve. 2000; 23(2):198-205

41. Schrag A, Trimble M, Quinn N, Bhatia K. The syndrome of fixed dystonia: an evaluation of 103 patients. Brain. 2004;127(Pt 10): 2360-72.

42. Fahn S, Williams DT. Psychogenic dystonia. Adv Neurol. 1988;50: 431-55.

43. Heiman GA, Ottman R, Saunders-Pullman RJ, Ozelius LJ, Risch NJ, Bressman SB. Increased risk for recurrent major depression in DYT1 dystonia mutation carriers. Neurology. 2004;63(4): 631-7.

44. Saunders-Pullman R, Shriberg J, Heiman G, et al. Myoclonus dystonia: possible association with obsessive-compulsive disorder and alcohol dependence. Neurology. 2002;58(2):242-5.

45. Cardoso F, Jankovic J. Peripherally induced tremor and parkinsonism. Arch Neurol. 1995;52(3):263-70.

46. Chen R, Cohen LG, Hallett M. Nervous system reorganization following injury. Neuroscience. 2002;111(4):761-73.

47. Micheli F, Torres L, Diaz M, Scorticati MC, Diaz S. Delayed onset limb dystonia following electric injury. Parkinsonism Relat Disord. 1998 Jun;4(1):39-42. 
48. Burke RE, Fahn S, Gold AP. Delayed-onset dystonia in patients with "static" encephalopathy. J Neurol Neurosurg Psychiatry. 1980;43(9):789-97.

49. Pettigrew LC, Jankovic J. Hemidystonia: a report of 22 patients and a review of the literature. J Neurol Neurosurg Psychiatry. 1985; 48(7):650-7.

50. Chuang C, Fahn S, Frucht SJ. The natural history and treatment of acquired hemidystonia: report of 33 cases and review of the literature. J Neurol Neurosurg Psychiatry. 2002;72(1):59-67.

51. Merskey H, Bogduk N. Classification of chronic pain: descriptions of chronic pain syndromes and definitions of pain terms. 2nd ed. Seattle: IASP Press; 1994.

52. Bruehl S, Harden RN, Galer BS, et al. External validation of IASP diagnostic criteria for Complex Regional Pain Syndrome and proposed research diagnostic criteria. International Association for the Study of Pain. Pain. 1999;81(1-2):147-54.

53. Marsden CD, Obeso JA, Traub MM, Rothwell JC, Kranz H, La Cruz F. Muscle spasms associated with Sudeck's atrophy after injury. Br Med J (Clin Res Ed). 1984;288(6412):173-6.

54. Bhatia KP, Bhatt MH, Marsden CD. The causalgia-dystonia syndrome. Brain. 1993;116(Pt 4):843-51.

55. Schwartzman RJ, Kerrigan J. The movement disorder of reflex sympathetic dystrophy. Neurology. 1990;40(1):57-61 .

56. van Rijn MA, Marinus J, Putter H, van Hilten JJ. Onset and progression of dystonia in complex regional pain syndrome. Pain. 2007;130(3):287-93.

57. Birklein F, Riedl B, Sieweke N, Weber M, Neundörfer B. Neurological findings in complex regional pain syndromes-analysis of 145 cases. Acta Neurol Scand. 2000;101(4):262-9

58. Schott GD. Peripherally-triggered CRPS and dystonia. Pain. 2007; 130(3):203-7.

59. Raja SN. Motor dysfunction in CRPS and its treatment. Pain. 2009; 143(1-2):3-4.

60. van Hilten JJ, van de Beek WJ, Vein AA, van Dijk JG, Middelkoop HA. Clinical aspects of multifocal or generalized tonic dystonia in reflex sympathetic dystrophy. Neurology. 2001;56(12): $1762-5$.

61. Reedijk WB, van Rijn MA, Roelofs K, Tuijl JP, Marinus J, van Hilten JJ. Psychological features of patients with complex regional pain syndrome type I related dystonia. Mov Disord. 2008;23(11):1551-9.

62. van der Laan L, van Spaendonck K, Horstink MW, Goris RJ. The SymptomChecklist-90 Revised questionnaire: no psychological profiles in complex regional pain syndrome-dystonia. J Pain Symptom Manage. 1999;17(5):357-62.

63. van de Beek WJ, Vein A, Hilgevoord AA, van Dijk JG, van Hilten BJ. Neurophysiologic aspects of patients with generalized or multifocal tonic dystonia of reflex sympathetic dystrophy. J Clin Neurophysiol. 2002;19(1):77-83.

64. Schwenkreis P, Janssen F, Rommel O, et al. Bilateral motor cortex disinhibition in complex regional pain syndrome (CRPS) type I of the hand. Neurology. 2003;61(4):515-9.

65. Topp KS, Byl NN. Movement dysfunction following repetitive hand opening and closing: anatomical analysis in owl monkeys. Mov Disord. 1999; 14(2):295-306.

66. Coq JO, Barr AE, Strata F, et al. Peripheral and central changes combine to induce motor behavioral deficits in a moderate repetition task. Exp Neurol. 2009;220(2):234-45.

67. Elliott MB, Barr AE, Barbe MF. Spinal substance P and neurokinin1 increase with high repetition reaching. Neurosci Lett. 2009;454 (1):33-7.

68. Reilly JA, Hallett M, Cohen LG, Tarkka IM, Dang N. The N30 component of somatosensory evoked potentials in patients with dystonia. Electroencephalogr Clin Neurophysiol. 1992;84(3): 243-7.

69. Tempel LW, Perlmutter JS. Abnormal vibration-induced cerebral blood flow responses in idiopathic dystonia. Brain. 1990;113(Pt 3):691-707.
70. Kaji R, Rothwell JC, Katayama M, et al. Tonic vibration reflex and muscle afferent block in writer's cramp. Ann Neurol. 1995;38 (2): $155-62$

71. Hallett M. How does botulinum toxin work? Ann Neurol. 2000;48 (1):7-8.

72. Birklein F, Schmelz M. Neuropeptides, neurogenic inflammation and complex regional pain syndrome (CRPS). Neurosci Lett. 2008;437(3):199-202.

73. Oyen WJ, Arntz IE, Claessens RM, Van der Meer JW, Corstens FH, Goris RJ. Reflex sympathetic dystrophy of the hand: an excessive inflammatory response? Pain. 1993;55(2):151-7.

74. Kimura S, Honda M, Tanabe M, Ono H. Noxious stimuli evoke a biphasic flexor reflex composed of A delta-fiber-mediated shortlatency and C-fiber-mediated long-latency withdrawal movements in mice. J Pharmacol Sci. 2004;95(1):94-100.

75. Hultborn H. Spinal reflexes, mechanisms and concepts: from Eccles to Lundberg and beyond. Prog Neurobiol. 2006;78(3-5): 215-32.

76. Schouenborg J. Learning in sensorimotor circuits. Curr Opin Neurobiol. 2004;14(6):693-7.

77. Parsons AM, Honda CN, Jia YP, et al. Spinal NK1 receptors contribute to the increased excitability of the nociceptive flexor reflex during persistent peripheral inflammation. Brain Res. 1996;739(1-2):263-75

78. Saito K, Konishi S, Otsuka M. Antagonism between Lioresal and substance $\mathrm{P}$ in rat spinal cord. Brain Res. 1975;97(1):177-80.

79. van Hilten BJ, van de Beek WJ, Hoff JI, Voormolen JH, Delhaas EM. Intrathecal baclofen for the treatment of dystonia in patients with reflex sympathetic dystrophy. N Engl J Med. 2000;343 (9):625-30.

80. Chudler EH, Dong WK. The role of the basal ganglia in nociception and pain. Pain. 1995;60(1):3-38.

81. Jones AK, Brown WD, Friston KJ, Qi LY, Frackowiak RS. Cortical and subcortical localization of response to pain in man using positron emission tomography. Proc Biol Sci. 1991;244(1309): 39-44

82. Borsook D, Moulton EA, Tully S, Schmahmann JD, Becerra L. Human cerebellar responses to brush and heat stimuli in healthy and neuropathic pain subjects. Cerebellum. 2008;7(3):252-72.

83. Dauer WT, Burke RE, Greene P, Fahn S. Current concepts on the clinical features, aetiology and management of idiopathic cervical dystonia. Brain. 1998;121(Pt 4):547-60.

84. Braz JM, Nassar MA, Wood JN, Basbaum AI. Parallel "pain" pathways arise from subpopulations of primary afferent nociceptor. Neuron. 2005;47(6):787-93.

85. Byl NN, Merzenich MM, Cheung S, Bedenbaugh P, Nagarajan SS, Jenkins WM. A primate model for studying focal dystonia and repetitive strain injury: effects on the primary somatosensory cortex. Phys Ther. 1997;77(3):269-84.

86. Gieteling EW, van Rijn MA, de Jong BM, et al. Cerebral activation during motor imagery in complex regional pain syndrome type 1 with dystonia. Pain. 2008;134(3):302-9.

87. Eisenberg E, Chistyakov AV, Yudashkin M, Kaplan B, Hafner H, Feinsod M. Evidence for cortical hyperexcitability of the affected limb representation area in CRPS: a psychophysical and transcranial magnetic stimulation study. Pain. 2005;113(1-2): 99-105.

88. Juottonen K, Gockel M, Silén T, Hurri H, Hari R, Forss N. Altered central sensorimotor processing in patients with complex regional pain syndrome. Pain. 2002;98(3):315-23.

89. Ji RR, Woolf CJ. Neuronal plasticity and signal transduction in nociceptive neurons: implications for the initiation and maintenance of pathological pain. Neurobiol Dis. 2001;8(1): $1-10$. 